As fases da lua e a mitologia tupi-guarani: um caminho entre a ciência e a cultura numa aula para o ensino fundamental

Anna Mara Ferreira Maciel

Graduanda, UFLA, Brasil

annamara10@hotmail.com

Nayara Pereira

Graduanda, UFLA, Brasil

nayarap062@gmail.com

Camila Oliveira Lourenço

Graduanda, UFLA, Brasil

camila_olourenco@hotmail.com

Antonio Fernandes Nascimento Junior

Professor Doutor, UFLA, Brasil

toni_nascimento@yahoo.com.br 


\title{
Periódica Eletrânica
}

\section{Fórum Ambiental}

Volume 14, Número 2, 2018

ISSN 1980-0827

\author{
da Alta Paulista
}

\section{RESUMO}

O presente trabalho relata uma atividade desenvolvida no ano de 2015 , durante a disciplina de Metodologia do Ensino de Ciências do curso de Licenciatura em Ciências Biológicas da Universidade Federal de Lavras (UFLA). 0 objetivo foi construir conhecimentos sobre o tema fases da lua, tendo como estratégias pedagógicas uma narrativa mítica indígena e uma dinâmica. Após o desenvolvimento da aula foi realizada uma avaliação com os alunos da disciplina. As falas dos alunos participantes foram analisadas a partir da técnica de análise de conteúdo e da categorização. As categorias construídas a partir das análises foram: Dinâmica, Interação professor-aluno e Cultura Indígena. Pode-se perceber, a partir das análises que, a dinâmica se configura como metodologia interessante no processo de construção do conhecimento, bem como a interação entre professor-aluno. Além disso, a inserção da cultura indígena nas aulas permite que o estudante reconheça o contexto em que vive por meio da identificação da cultura indígena e, assim, compreenda sua própria história.

Palavras chave: Ensino de Ciências, Fases da Lua, Mitologia, Dinâmica.

\section{ASBSTRACT}

The present work reports an activity developed in the year 2015, during the discipline of Science Teaching Methodology of the Licentiate course in Biological Sciences of the Federal University of Lavras (UFLA). The objective was to build knowledge on the theme phases of the moon, taking as pedagogical strategies an indigenous mythical narrative and a dynamic. After the development of the class an evaluation was made with the students of the discipline. The participant students' speeches were analyzed using the technique of content analysis and categorization. The categories constructed from the analyzes were: Dynamics, teacher-student interaction and Indigenous Culture. It can be seen from the analysis that the dynamics is an interesting methodology in the process of knowledge construction, as well as the interaction between teacher-student. In addition, the insertion of the indigenous culture in the classes allows the student to recognize the context in which he lives by identifying the indigenous culture and, thus, to understand his own history.

Keywords: Science Teaching, Phases of the Moon, Mythology, Dynamics.

\section{RESUMEN}

El presente trabajo relata una actividad desarrollada en el año 2015, durante la disciplina de Metodología de la Enseñanza de Ciencias del curso de Licenciatura en Ciencias Biológicas de la Universidad Federal de Lavras (UFLA). El objetivo fue construir conocimientos sobre el tema fases de la luna, teniendo como estrategias pedagógicas una narrativa mítica indígena y una dinámica. Después del desarrollo de la clase se realizó una evaluación con los alumnos de la disciplina. Las palabras de los alumnos participantes fueron analizadas a partir de la técnica de análisis de contenido y de la categorización. Las categorías construidas a partir de los análisis fueron: Dinámica, Interacción profesor-alumno y Cultura Indígena. Se puede percibir, a partir de los análisis que, la dinámica se configura como metodología interesante en el proceso de construcción del conocimiento, así como la interacción entre profesor-alumno. Además, la inserción de la cultura indígena en las aulas permite que el estudiante reconozca el contexto en que vive por medio de la identificación de la cultura indígena y, así, comprenda su propia historia. Palabras clave: Enseñanza de Ciencias, Fases de la Luna, Mitología, Dinámica. 


\section{Periódica Eletrânica}

\section{1- INTRODUÇÃO}

Quando nos deparamos com o processo de ensinar Ciências é necessário realizar uma reflexão sobre o que é a Educação em Ciências, como Cachapuz e colaboradores (2004) nos trazem como argumentação e reflexão. Os autores argumentam sobre uma Educação em Ciências de forma interdisciplinar, propondo assim orientações para o Ensino de Ciências. Para eles, o que os estudantes da escola básica aprendem hoje é apenas uma retórica de conclusões, pois adquirir os conhecimentos científicos não leva à compreensão da ciência de uma forma holística, além disso, o ensino de ciências deve ser de forma contextualizada para que todos os assuntos possam interessar os estudantes, para que eles possam não só identificar os conteúdos em seu cotidiano, como também aplicá-los em sua realidade social. Outro ponto tratado pelos autores é a dimensão sócio-construtivista do ensino de ciências, a qual defende que a aprendizagem se relaciona com um processo social e cultural mediado.

Apesar de identificarmos propostas para o Ensino de Ciências, Pereira e Fontoura (2013), argumentam que no Brasil o ensino fundamental, principalmente, apresenta o currículo estruturado de forma fragmentada, dificultando uma abordagem interdisciplinar durante o processo de ensino-aprendizagem. Assim, percebe-se uma dificuldade com relação a um Ensino de Ciências crítico e contextualizado, pois se torna incapaz de enfrentar a complexidade das problemáticas ambientais.

Pensando no currículo escolar que envolve o Ensino de Ciências, um dos temas que permeiam este currículo é a temática astronomia. E, segundo Lattari e Trevisan (1999), o ensino dos astros no Ensino Fundamental é imprescindível para o processo de aprendizagem, o desenvolvimento da curiosidade e o interesse na observação dos fenômenos astronômicos e então se torna importante criar situações-problema, choques de conhecimentos prévios entre os alunos para que seja despertado o interesse na busca por conhecimento, porém Langhi e Nardi (2007), dizem que, dentre os temas que permeiam o ensino de Astronomia nas escolas, podemos encontrar erros conceituais nos livros didáticos que servem de parâmetro para o ensino das temáticas estações do ano, as fases da lua, movimentos e inclinação da terra, entre outros que são relevantes para o processo de ensino-aprendizagem dos alunos da escola básica. Outra problemática em relação ao ensino de astronomia é a dificuldade dos alunos se apropriarem dos conteúdos relacionados ao tema. A priori, a dificuldade se inicia em imaginar um referencial fora da terra, ter uma visão espacial e um maior grau de abstração que é pouco habitual nas escolas e culmina então na resistência ao entendimento dos movimentos terrestres e dos corpos celestes (SILVA, 2009).

Além destas problemáticas que o livro didático apresenta com relação às temáticas que fazem parte da Astronomia e a dificuldade de abstração dos estudantes, o desenvolvimento do tema fases da lua, em específico, se torna problemático em sala de aula por envolver noções de espaço, proporções, observações, relações de movimentos da Terra e da Lua, além de reflexão solar, pode ser muito complexo, de acordo com Kriner (2004).

Identificando as problemáticas com relação ao Ensino de Ciências foi proposto, durante o desenvolvimento da disciplina de Metodologia do Ensino de Ciências, o planejamento e 
realização de uma prática a fim de construir conhecimentos sobre o tema Fases da Lua. A disciplina faz parte da grade curricular do curso de Licenciatura em Ciências Biológicas da Universidade Federal de Lavras (UFLA), Minas Gerais. Para o desenvolvimento da aula já construída foi utilizado uma narrativa mítica e uma dinâmica, pois entende-se que é de grande importância à inserção de recursos pedagógicos que agucem a curiosidade dos alunos. Neste sentido, podemos pensar no uso das narrativas míticas como recursos pedagógicos interessantes para trabalhar com o ensino de Astronomia. Conforme Fonseca e colaboradores (2007) trabalhar com a população indígena e seus mitos se torna um instrumento importante, pois permite a construção de uma nova forma de perceber a ciência, que até então, não valoriza o conhecimento empírico. Sendo assim, os mitos, conforme Leal e Gouvêa (2002), uma das considerações que podemos realizar com relação a eles é o caráter afirmativo do mito, nos reportando às narrativas tradicionais que, ao longo do tempo, são transmitidas de geração em geração. A segunda consideração

De acordo com Testa (2011), a presença de conhecimentos relacionados à cultura indígena só foram incorporados à escola por meio do engajamento dos indígenas, na luta pelos seus direitos, assim essa conquista possibilitou o acessos dos estudantes a conhecimentos e informações culturais que contribuem para o reconhecimento da pluralidade cultural e o respeito às diferenças, porém segundo Souza (2008), os professores de Ciências e Biologia quando trazem o tema de cultura indígena na sala de aula, não relacionam essa cultura com os conhecimentos científicos, o que leva a uma sobreposição de um conhecimento sobre o outro. Outro ponto que necessita ser destacado é que, muitas vezes, o docente traz os conhecimentos da cultura indígena provenientes do senso comum, assim percebe-se a importância de práticas que permitem conhecer a cultura no processo de formação inicial de professores.

Além da narrativa mítica como recurso pedagógico, podemos destacar a dinâmica também como ferramenta interessante de ensino, pois segundo Dallabona e Mendes (2004), a ação de buscar, de compartilhar e de agir permite a educação dos seres humanos e ela se faz a partir da comunicação e interação entre os sujeitos e é por meio das atividades lúdicas, como a própria dinâmica, que o aluno comunica consigo e com os outros e então, constrói conhecimentos por meio destas relações sociais. A dinâmica, segundo Souza e colaboradores (2011), auxilia no processo de construção de conhecimentos, permitindo o desenvolvimento da interação social, além disso, a aprendizagem se faz de forma significativa na medida em que torna a aula lúdica. Essa ferramenta, ainda de acordo com os autores, permite facilitar a interação entre professor-aluno e aluno- aluno, promovendo uma facilidade no processo de ensino-aprendizagem.

Assim, o objetivo da aula foi construir conhecimentos sobre o tema fases da lua, a partir de questionamentos que, permitiram a inserção da narrativa mítica tupi-guarani "Jaci Guaraci" e de uma dinâmica para melhor compreensão do processo de modificação da imagem da lua. A atividade foi desenvolvida no ano de 2015 com os alunos da Metodologia do Ensino de Ciências do curso de Licenciatura em Ciências Biológicas da Universidade Federal de Lavras (UFLA), Minas Gerais. 


\section{2- DESENVOLVIMENTO}

\section{Proposta da disciplina}

A disciplina de Metodologia do Ensino de Ciências é ofertada no terceiro período do curso de Licenciatura em Ciências Biológicas da UFLA. Ela permite realizar discussões sobre os temas que permeiam a atuação docente como a importância dos recursos pedagógicos, do planejamento de uma aula e a realização desta prática.

No segundo semestre do ano de 2015 foi proposta a construção de uma aula, partindo dos temas que envolvem as Ciências Naturais abordados pelos Parâmetros Curriculares Nacionais (PCN's) do Ensino Fundamental. A turma foi dividida em duplas e cada uma dessas duplas ficou responsável por trabalhar com um tema do PCN. Sendo assim, as duas das estudantes que participam desse trabalho ficaram responsáveis por trabalhar o tema Fases da Lua. Assim foi planejada uma atividade utilizando uma narrativa mítica indígena e uma dinâmica a fim de construir conhecimentos sobre as Fases da Lua.

Após este momento, a aula foi apresentada para os bolsistas do Programa Institucional de Bolsas de Iniciação à Docência (PIBID), subprojeto Ciências Biológicas, com o objetivo de que os participantes do programa contribuíssem para a construção da aula no sentido de direcionar e realizar ajustes com relação aos recursos pedagógicos, ao conteúdo, a avaliação e sequência da aula.

\section{Descrição da aula}

A atividade foi dividida em algumas etapas. No primeiro momento, foram feitos questionamentos aos alunos, eles eram: Vocês têm costume de olhar para o céu a noite? Vocês gostam da lua? A Lua muda? Já ouviram histórias antigas sobre o céu ou a lua?Após a realização do último questionamento os estudantes relataram que já tinham ouvido histórias sobre o céu e a lua. Assim, eles foram questionados sobre o conhecimento da história de Jaci e Guaraci (a descrição da narrativa mítica segue abaixo) uma mitologia tupi-guarani, porém nenhum aluno conhecia.

A Lenda do Sol e da Lua

Uma infinita escuridão cobria todo o universo. Então, Deus criou o sol, Guaraci, para iluminar todo o universo com a sua luz.

Certa vez, Guaraci ficou cansado e precisou dormir. Enquanto fez isso, a escuridão voltou a se impor no universo.

Então, Deus criou Jaci, a Lua para iluminar o universo enquanto Guaraci, o sol, estivesse dormindo.

Num breve instante, enquanto Guaraci acordava e Jaci ia dormir os dois se viram e se apaixonaram. Mas, infelizmente, não podiam ficar juntos.

Então Deus criou Rudá, o amor, para ser o mensageiro do casal. O amor, Rudá, não conhecia a escuridão, nem o impossível. Dia ou noite Rudá podia dizer à Lua o quanto o Sol a amava e podia dizer ao Sol que o seu amor era correspondido. 


\title{
Periódica Eletrônica
}

\section{Fórum Ambiental}

Volume 14, Número 2, 2018

\author{
da Alta Paulista
}

ISSN 1980-0827

Atendendo a um pedido de amor do Sol, Deus criou as estrelas para que pudesse fazer companhia à Jaci, a Lua, durante a noite.

E assim, segundo os índios brasileiros, nasceu o Céu e todas as coisas que lá existem.

Adaptação da versão da lenda indígena coletada por Couto de Magalhães (Christiane Angelotti, 2011).

No segundo momento da atividade a mitologia foi contada de maneira ilustrativa (Figura 1). Após este momento, a turma foi dividida em três grupos e foram entregues os calendários atuais contendo nestes, as Fases da Lua (Figura 2). Novamente, foram feitos questionamentos aos alunos, eles eram: "Como o calendário é dividido?", "O que mais além dos dias e meses vocês podem observar?". Foram feitas perguntas até que os estudantes citassem a Lua.

Após o reconhecimento das Fases da Lua como uma forma de divisão no calendário, os alunos, utilizando um lápis de cor, marcaram o início de cada lua (Figura 3) para que pudessem perceber de quanto em quanto tempo ocorria uma Fase Lunar.

Em um terceiro momento, foi realizada uma dinâmica. Foram convocados quatro voluntários, um deles intitulado a Terra e ele deveria se sentar no chão, o outro foi intitulado de Lua e segurava uma esfera preta, e ainda outros dois que fizeram o papel de sol, utilizando uma lanterna para emitir a luz solar (Figura 4). Após se posicionarem, foi informado para o aluno Lua começar a girar devagar em torno da Terra, enquanto as professoras iluminavam a bola (Figura 5). Durante a dinâmica foram feitos vários questionamentos aos discentes, como: "O que vocês estão vendo na Lua?", "A parte iluminada está crescendo ou diminuindo?". O processo foi feito duas vezes para melhor entendimento de todos.

Ao término da dinâmica, os estudantes trouxeram uma questão sobre o processo de Eclipse e então os educandos que faziam papel de Terra foram instruídos a se levantarem para que o fenômeno fosse demonstrado, sendo assim, a Terra ofuscava a luz do Sol que deveria refletir na lua, deixando-a assim, sem iluminação.

Após este momento foi pedido para que os estudantes fizessem uma atividade avaliativa (Figura 6), desenhando uma fase da lua ou algo que foi contado durante a narrativa mítica que chamou atenção dos participantes, justificando o motivo da escolha. Uma dessas avaliações está representada na Figura 6. Após esta atividade foi pedido aos estudantes para que descrevessem os pontos positivos e os pontos a serem melhorados.

Figura 1: Imagens para ilustrar a Mitologia

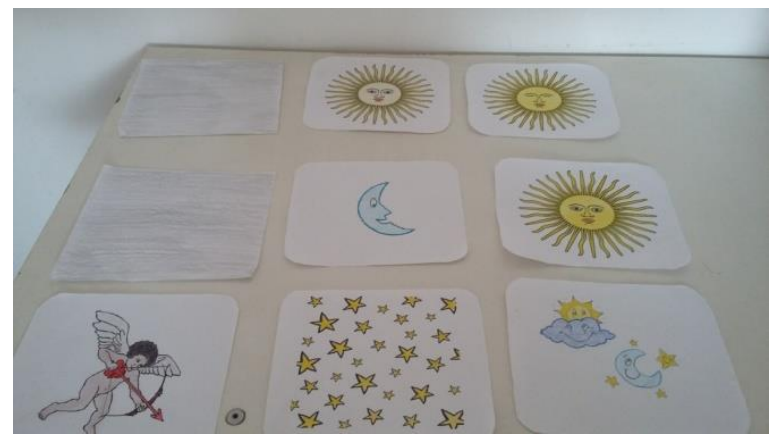

Fonte: Antonio Fernandes Nascimento Junior, 2015
Figura 2: Calendário para ilustrar as Fases da Lua

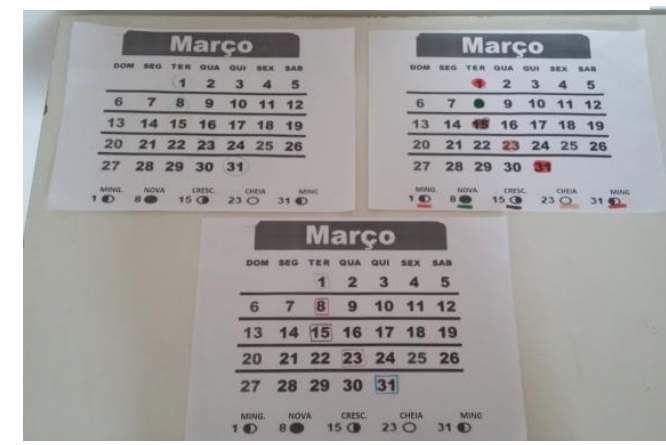

Fonte: Antonio Fernandes Nascimento Junior, 2015 


\section{Periódica Eletrônica \\ Fórum Ambiental \\ Volume 14, Número 2, 2018 \\ da Alia Paulista \\ ISSN 1980-0827}

Figura 3: Alunos marcando o início de cada fase da lua

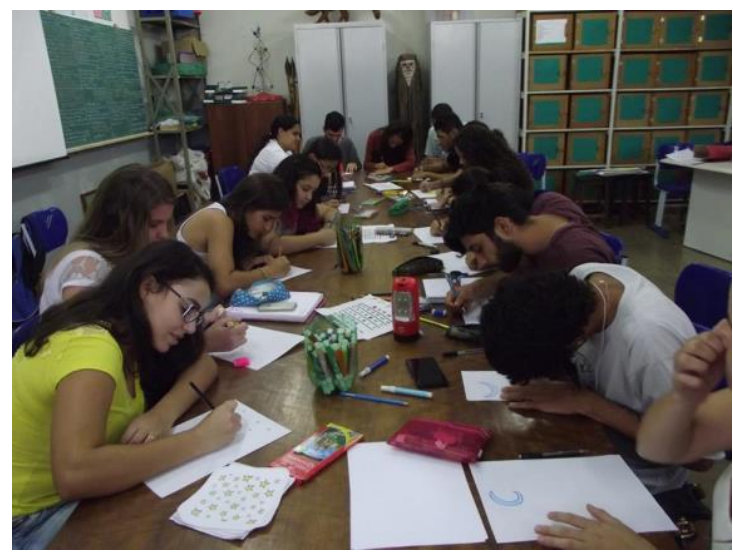

Fonte: Antonio Fernandes Nascimento Junior, 2015
Figura 4: Alunos participando da dinâmica

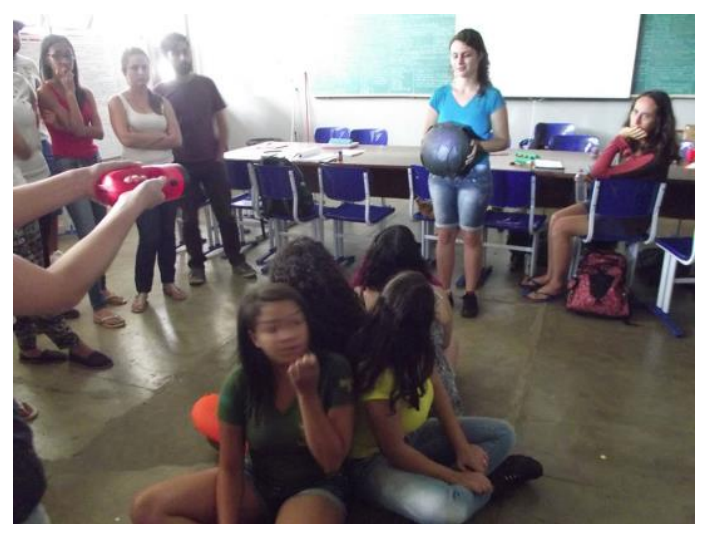

Fonte: Antonio Fernandes Nascimento Junior. 2015

Figura 5: Lua sendo iluminada

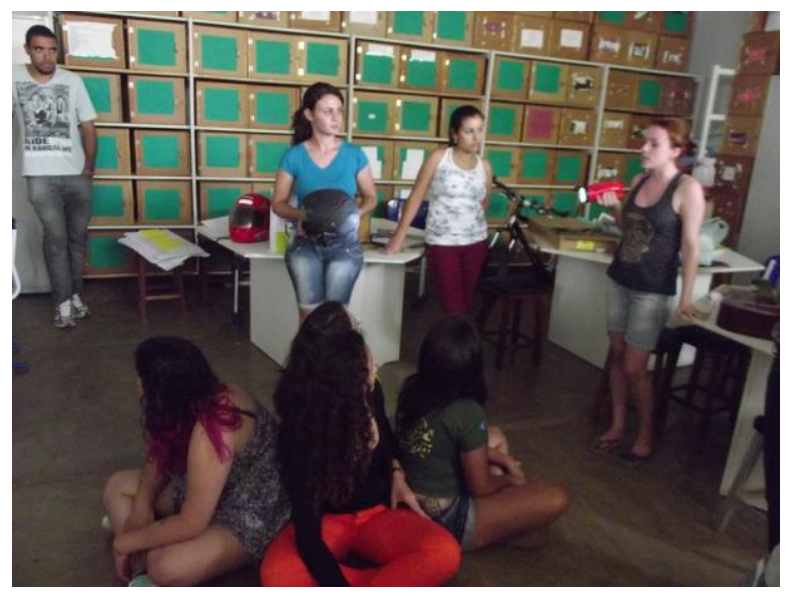

Fonte: Antonio Fernandes Nascimento Junior, 2015 
Figura 6: Desenho avaliativo

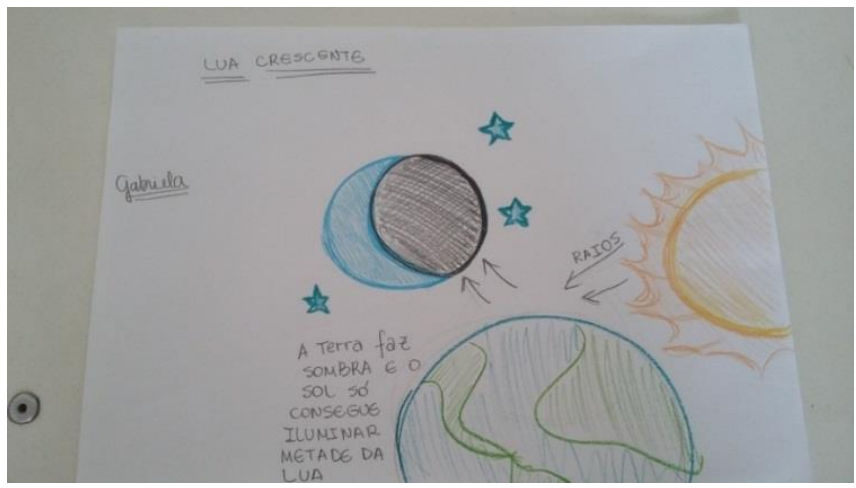

Fonte: Antonio Fernandes Nascimento Junior, 2015

\section{3- METODOLOGIA}

A análise da atividade foi realizada a partir dos pontos positivos e dos pontos a serem melhorados no desenvolvimento da aula, trazidos pelos alunos da própria disciplina de Metodologia do Ensino de Ciências que também participaram do desenvolvimento da atividade. Para o processo de análise embasou-se na metodologia de pesquisa qualitativa. E na realização da análise das falas dos estudantes foi utilizada a análise de conteúdo e como procedimento metodológico a categorização das falas (MINAYO E COLABORADORES, 2016).

\section{4- RESULTADOS E DISCUSSÃO}

Foram analisadas nove falas dos participantes. Durante o processo de análise das falas os participantes da atividade foram identificados com a letra $A$, seguida de uma numeração.

A1: "A metodologia aplicada foi bem dinâmica, trazendo para o ambiente escolar os conhecimentos prévios construímos desde muito pequenos, mostrando o quanto o conhecimento popular influencia em estudos científicos. Além da carga cultural indígena brasileira que trouxeram para a sala, suprindo assim a necessidade que o PCN traz em passar os temas transversais. Ainda devemos ressaltar que elas conseguiram fazer com que todos os alunos participassem, sem perder o controle da turma e sem ultrapassar muito o tempo planejado."

A2: "A aula foi muito interessante, pois usaram uma dinâmica com as fases da lua fácil de compreender, já que a aula é preparada para crianças, usando a cultura, história tupi guarani, para introduzir o assunto que faz com que o aluno aprenda a mais do que a matéria." 
A3: "A apresentação das alunas foi bem interessante, pois a partir da ajuda dos colegas de sala, elas fizeram uma representação das fases da lua mostrando na pratica e explicando como funcionam, como acontecem as fases a partir do nosso calendário, alem de contar algumas historias, incluindo uma historia bem interessante sobre a tribo tupi guarani, uma das tribos de nosso pais, de como a lua foi criada."

A4: "O exemplo que elas demonstraram foi bastante interessante, porque para alunos menores esse assunto sobre fases da lua é mais complexo. E com a apresentação que elas fizeram, o entendimento dos alunos, creio que fique mais fácil. Uma metodologia pratica e fácil de introduzir entre os alunos."

A5: "A aula teve um desenvolvimento bastante interativo, criativo, onde pude compreender a matéria, despertou também maiores curiosidades, demonstraram um domínio e segurança no que estavam falando."

A6: "A aula foi muito interativa bastante didática de modo que despertou o interesse dos alunos sobre as fases da lua, se preocuparam bastante com entendimento dos alunos."

A7: "Com essa aula foi possível compreender de uma forma simples e dinâmica como ocorre as fases da lua e como elas interferem na Terra.Todos os alunos puderam participar dizendo o que sabiam e entediam sobre as fases da lua em relação ao Sol e a Terra."

A8: "A aula foi apresentada de forma bem objetiva. A história contada no início despertou atenção e interesse nos alunos. A dinâmica para apresentar as fases da lua alcançou bem o objetivo de explicar cada uma delas, ficou bem claro aos alunos como ocorre cada fase da lua, e houve explicações bem claras sobre algumas coisas como eclipse lunar e solar. E mostrar-nos o calendário foi bem legal, pois nos fez ver a influencia das fases da lua no nosso dia a dia.

A9: "O grupo cumpriu com os seus objetivos, de forma clara apresentou os conteúdos, sendo dessa forma uma aula bem direcionada para o nível escolar em que a matéria seria lecionada. Os questionamentos ao longo da aula (constantes) considero bastante importante, pois levantamos conhecimentos prévios dos alunos e permitem a interação entre a turma e o professor. A metodologia foi eficaz, bem clara, o que é muito bom, considerando o público de destino. A relação com a mitologia indígena brasileira foi mesmo uma boa forma de inserir elementos culturais importantes provando que o ensino é mais que conteudista e deve envolver outras ferramentas e elementos.".

A partir das análises foram elaboradas categorias que estão expressas no quadro abaixo: 


\section{Periódica Eletrônica}

\section{Fórum Ambiental}

Quadro 1 : Categorias, descrição e frequência

\begin{tabular}{|l|l|c|}
\hline \multicolumn{1}{|c|}{ Categoria } & \multicolumn{1}{|c|}{ Descrição } & Frequência \\
\hline Dinâmica & $\begin{array}{l}\text { A categoria contém as falas dos estudantes } \\
\text { que tratam da dinâmica como importante } \\
\text { para o processo de construção dos } \\
\text { conhecimentos. }\end{array}$ & 7 \\
\hline Interação & $\begin{array}{l}\text { A categoria apresenta os elementos que } \\
\text { tratam da atividade como importante para } \\
\text { a interação entre aluno- conhecimento e } \\
\text { discente- professor. }\end{array}$ & \\
\hline Cultura indígena & $\begin{array}{l}\text { A categoria cultura indígena abarca as falas } \\
\text { dos participantes que trazem o assunto } \\
\text { como tema transversal e que deve ser } \\
\text { abordado nas escolas conforme previsto } \\
\text { pelo PCN. }\end{array}$ & \\
\hline
\end{tabular}

Fonte: AUTORAL, 2018

Os participantes da atividade trouxeram a dinâmica realizada como uma estratégia interessante para o processo de construção de conhecimentos. Neste sentido, Bozelli e Nadir (2009) trazem que, as estratégias didático-pedagógicas devem permitir um contexto de discurso entre professor-aluno e este irá interferir na construção de conhecimentos na sala de aula, assim, para que os estudantes se apropriem de uma linguagem científica plausível é preciso que criemos espaços que possibilitem esta apropriação. De acordo com Pereira e Fontoura (2013), as dinâmicas de grupo apresentam características semelhantes aos jogos e assim elas respondem a objetivos específicos do processo de ensino-aprendizagem e permite então recriar os conhecimentos coletivamente e até mesmo individualmente. Além disso, segundo os autores, trabalhar com a dinâmica permite uma transformação nas concepções prévias dos estudantes com relação ao conhecimento a ser construído, promovendo assim uma ampliação destes conhecimentos. Outra questão interessante que envolve as práticas de dinâmicas em grupo é a possibilidade de facilitar o ensino de Ciências e ainda incentivar a criatividade e permitir atividades interdisciplinares.

Outro ponto trazido pelos estudantes foi com relação a interação entre aluno- conhecimento e docente-discente, proporcionada pelas atividades realizadas na sala de aula. Assim, Freire (2000) argumenta que, a interação é uma importante ferramenta no momento do processo de ensino-aprendizagem, pois quando há uma relação entre dois sujeitos, no caso, o professor e o aluno, podemos perceber um maior interesse do estudante em interagir durante as atividades realizadas e o agente responsável por esta interação é o próprio docente que, neste momento, é o mediador entre o sujeito aluno e o objeto conhecimento.

Conforme Tassoni e Leite (2000) é no vínculo estabelecido entre a criança e o adulto que se faz a aprendizagem e pensando especificamente na aprendizagem escolar é a relação entre o professor e aluno que permite esse processo, pois além desta interação também estão envolvidos os conteúdos escolares, os livros e o processo de escrita. Portanto, é possível concluir que por meio do intenso processo de interação com o meio social os sujeitos passam a se apropriar dos objetos culturais e sociais que os cercam, pois ele começa a identificar o objeito de conhecimento e o seu significado. Assim, esse processo de identificação perpassa 
não só pelos aspectos cognitivos, mas também pelos aspectos afetivos e então podemos compreender que as investigações científicas se caracterizam pelos envolvimentos afetivos dos sujeitos no momento do ensino-aprendizagem.

A presença da temática indígena também foi trazida pelos estudantes no momento da avaliação. Eles trouxeram a importância de abordar o tema nas aulas, pois se configura como tema transversal, segundo o Parâmetro Curricular Nacional (BRASIL, 2000) e ainda permite que os estudantes reconheçam e valorizem essa cultura, já que faz parte da formação da sociedade brasileira. De acordo com os Parâmetros Curriculares Nacionais - Pluralidade Cultural (BRASIL, 2000), o assunto se configura como tema transversal e por isso este pode ser trabalhado em diversas disciplinas, transvergindo nas temáticas ética e trabalho e consumo. Outro aspecto que o documento traz é a importância do tema, pois quando inserido nas escolas, propõe compreender as diversidades étnica e cultura a qual a sociedade brasileira está inserida, assim é possível que o aluno reconheça o seu país como complexo e multifacetado.

Além disso, nas Diretrizes Curriculares Nacionais (BRASIL, 1993) é importante que a escola trabalhe com as diversas culturas presentes na sociedade brasileira, pois o intercâmbio entre as culturas é mutuamente enriquecedor no sentido de permitir reconhecer a diversidade destas culturas e como elas se relacionam entre si. Ferreira (1994) argumenta que é necessário reconhecer a ciência sob o olhar das diversas sociedades a partir da percepção do que elas estão construindo. Assim, é possível um distanciamento da ciência positivista e hegemônica construída durante esses anos, o que permite inserir as diversas sociedades durante o processo de desenvolvimento da ciência.

\section{5- CONSIDERAÇÕES FINAIS}

Após a análise das falas, pode-se perceber a importância de se inovar dentro da sala de aula, trabalhando com os recursos pedagógicos e com temas que são relevantes para a formação dos estudantes como indivíduos reflexivos e críticos que atuam de maneira ativa na sociedade a qual fazem parte e, assim, possam reconhecer suas origens. Neste sentido, foi possível reconhecer a importância da atividade desenvolvida na disciplina de Metodologia do Ensino de Ciências.

A dinâmica pôde ser identificada como recurso pedagógico interessante no processo de construção do conhecimento e na interação entre o discente e o docente, permitindo que aquele se interesse pelos conteúdos trabalhados durante as atividades. A partir de uma metodologia em que o professor abre espaço para os alunos participarem, eles começam a ter aproximação com o professor e a questionar assuntos além do que são tratados nos livros didáticos. Além disso, quando trabalhado como recurso pedagógico permite que os conhecimentos sejam recriados de forma coletiva e ainda promove a ampliação dos conhecimentos em ciências de forma criativa.

Durante o processo de desenvolvimento da atividade percebeu-se também uma interação entre professor-aluno, podendo identificar que os recursos pedagógicos permitiram esta interação. Neste sentido, é possível reconhecer que, captar a atenção do aluno é uma das 
grandes dificuldades que os professores têm enfrentado, visto que tudo é mais interessante do que o conteúdo apresentado, portanto possuir métodos que prioriza a interação com os alunos se torna relevante. Além disso, possuir práticas pedagógicas que prendam a atenção dos alunos é importante para que consigam ter desenvolvimento de suas capacidades, podendo assim, se apropriar do conteúdo abordado e conseguir discutir sobre os assuntos propostos pelo professor.

A inserção do tema transversal, cultura indígena, também foi um aspecto interessante. É uma temática que deve ser inserida nos currículos escolares, segundo os documentos que direcionam os conteúdos a serem trabalhados na escola, e que permite aos estudantes reconhecer o contexto em que vive por meio da identificação da cultura deste povo que formou a sociedade brasileira e assim ele pode compreender sua própria história.

\section{6- REFERÊNCIAS}

A LENDA DO SOL E DA LUA. Adaptação da versão da lenda indígena de Couto Magalhães por Christiane Angelotti, dezembro de 2011. Disponível em: http://sandrafichera.blogspot.com/2011/12/lenda-do-sol-e-da-lua.html. Acesso em: 9 jun. 2018.

BOZELLI, Fernanda Cátia; NARDI, Roberto. Ensino de Física, analogias e a dinâmica do contexto interativo discursivo em sala de aula. In: Roberto Nardi. (Org.). Ensino de Ciências e matemática I: temas sobre a formação de professores. 1ed. São Paulo: Cultura Acadêmica, 2009, p. 243-258.

BRASIL. MEC. Diretrizes para a política nacional de educação escolar indígena. Brasília. 1993. (Cadernos educação básica. Série institucional, 2).

BRASIL. Secretaria da educação fundamental. Parâmetros Curriculares Nacionais: Pluralidade Cultural/ Secretaria da Educação Fundamental, Brasília: MEC/SEF, 2000. 52 p.

BRASIL. Secretaria de Educação Fundamental. Parâmetros curriculares nacionais: Ciências Naturais / Secretaria de Educação Fundamental. Brasília: MEC /SEF, 1998.

CACHAPUZ, Antônio; PRAIA, João; JORGE, Manuela. Da educação em ciência às orientações para o ensino das ciências: um repensar epistemológico. Revista Ciência e Educação. v.10, n.3. p. 363-381. 2004.

DALLABONA, Sandra Regina; MENDES, Sueli Maria Schmitt. O lúdico na educação infantil. Revista de Divulgação Técnico-Científica do ICPG, Santa Catarina, v. 1, n. 107, p. 1-12. 2004.

FONSECA, Omar Martins da; PINTO, Simone Pinheiro; JURBERG, Claudia. Mitos e constelações indígenas, confeccionando um planetário de mão. In: REUNIÓN DE LA RED DE POPULARIZACIÓN DE LA CIENCIA Y LA TECNOLOGÍA EN AMÉRICA LATINA, 5. 2007, Caribe: RED POP - UNESCO, 2007. P. 1-8.

FREIRE, Flávio. A interação professor-aluno e suas implicações pedagógicas. Revista de Ensino, Educação e Ciências Humanas, Londrina, v. 1, n. 1, p. 115-121, jun. 2000. 


\title{
Periódica Eletrônica
}

\section{Fórum Ambiental}

Volume 14, Número 2, 2018

ISSN 1980-0827

\author{
da Alta Paulista
}

LANGHI, Rodolfo; NARDI, Roberto. Ensino de Astronomia: erros conceituais mais comuns presentes em livros didáticos de ciências. Caderno Brasileiro de Ensino de Física, v. 24, p. 87-111, 2007.

LATTARI, Cleiton Joni Benetti; TREVISAN, Rute Helena. Construindo o conhecimento do universo a partir do indivíduo ensino de astronomia no ensino fundamental. Atas do II ENPEC. Set, 1999.

MINAYO, Maria Cecília de Souza; DESLANDES, Suely Ferreira; GOMES, Romeu. Pesquisa Social: Teoria, método e criatividade. Petrópolis: Vozes, 2016. 95 p.

PEREIRA, Eliane Genésia Corrêa; FONTOURA, Helena Amaral da. Dinâmicas de grupo como recurso pedagógico no ensino de Ciências. Enseñanza de las Ciencias, v. 31, p. 2737-2741, 2013.

SEBASTIANI FERREIRA, Eduardo. A importância do conhecimento etnomatematico indigena na escola dos naoindios. Em aberto-temas:tendencias na educacao matematica, v. 62, p. 89-95, 1994.

SILVA, Tatiana da. Ensino a distância e tecnologias na educação: o estudo de fenômenos astronômicos. Caderno Brasileiro de Ensino de Física, v. 26, n. 3: p. 533-546, dez. 2009.

SOUZA, Jhanislei; TANJI, Jéssica; MACHADO, Beatriz. A Influência da Dinâmica de Grupo no Ambiente Escolar do Ensino Fundamental. In: ENCONTRO INTERNACIONAL DE PRODUÇÃO CIENTíFICA CESUMAR (EPCC). 7, 2011. Anais do Encontro Internacional de Produção Científica. Maringá: Cesumar, 2011, 5 p.

SOUZA, Selma Maria Ferreira de. Saberes docentes, saberes indígenas: Um estudo de caso sobre o ensino de ciências entre o povo xukuru do ororubá. 2008. 122 f. Dissertação (Mestrado em Ensino das Ciências) Universidade Federal Rural de Pernambuco, Orientadora: Zélia Jófili, 2008.

TASSONI, Elvira Cristina Martins; LEITE, Sérgio Antônio da Silva. Afetividade e aprendizagem: a relação professoraluno. In: REUNIÃO ANUAL DA ANPEd, n. 23, 2000, Caxambu, MG. Anuário-2000 Psicologia: análise e crítica da prática educacional. Goiás: Gráfica e Editora Vieira, 2000.

TESTA, Adriana Queiroz. A temática Indígena nas Escolas de São Paulo. 2011. 17. Desenvolvimento de material didático ou instrucional - Texto Paradidático (Doutoranda), Universidade Federal de São Paulo, São Paulo, 2011.

Apoios: CAPES E FAPEMIG 